\title{
Rotation schemes in politics - An experimental examination ${ }^{\#}$
}

\author{
Verena Waldner ${ }^{\dagger}$, Martin Kocher ${ }^{\dagger}$ and Matthias Sutter ${ }^{\S, *}$ \\ ${ }^{\dagger}$ University of Innsbruck \\ $\S$ Max-Planck-Institute for Research into Economic Systems Jena
}

\begin{abstract}
Rotation schemes in political organizations imply the temporary exclusion of some organization's members (outsiders) from decision-making. Consequently, only a fraction of members (insiders) has a direct influence in the decision-making process, whose results, however, concern and affect all members of the organization. Even though rotation schemes have been implemented in some political organizations - and are about to become more important in the European Union in the course of future enlargements - the political and economic consequences of rotation schemes, compared to an encompassing representation system, have not been thoroughly studied. We examine the effects of rotation schemes on the provision of a public good in groups. In particular, we study the degree of cooperation of (rotating) insiders and outsiders in an experiment and compare cooperation in rotation schemes with cooperation levels without rotation.
\end{abstract}

Keywords: rotation scheme, political organization, public good, exclusion, EU

\footnotetext{
\# We gratefully acknowledge financial support from the Center for Experimental Economics at the University of Innsbruck (sponsored by Raiffeisen Landesbank Tirol) and from the Austrian National Bank (through Jubiläumsfonds-Project Nr. 8487).

* Corresponding author. Address: Max Planck Institute for Research into Economic Systems, Strategic Interaction Group, Kahlaische Strasse 10, D-07745 Jena, Germany, phone: +49 3641686 642; fax: +49 3641 686 623; e-mail: sutter@mpiew-jena.mpg.de .
} 


\section{Introduction}

Collective decision-making in large political organizations often faces a tradeoff between the representation of all members in the decision-making process and the efficiency of it. Representation refers to the involvement of (all) members in the process of deliberation and decision-making, whereas efficiency dwells upon the costs of decision-making that is in general increasing in the number of participating agents (Buchanan and Tullock, 1962; Wieser, 2001). More specifially the more parties are involved in voting on collective decisions, the higher are typically the costs of negotiations, which takes place before the actual vote, and the more difficult and costly it can become to change the status quo of legislation in the vote (Felsenthal and Machover, 2001).

Rotation schemes have been proposed, and in some notable cases implemented, as a remedy for the representation/efficiency-dilemma. For instance, in the United Nations (UN) Security Council, besides the five permanent members, there are 10 members elected by the General Assembly for two-year terms. The non-permanent members are, therefore, represented under a (flexible) rotation scheme. A strict rotation scheme has been proposed in the EU's Treaty of Nice for the members of the EU-Commission as soon as the EU has 27 or more member states. ${ }^{1}$ In addition to provisions for the EU Commission, there is an ongoing discussion on introducing a rotation scheme in the European Central Bank's (ECB) Governing Council (Baldwin et al., 2001; de Grauwe, 2002; Heisenberg, 2003), as it is already customary for the U.S. Federal Reserve Board, where voting rights are restricted to a limited number of Governors.

In more general terms, rotation schemes in political organizations imply the temporary exclusion of some organization's members (henceforth called outsiders) from decisionmaking. Consequently, only a fraction of members (insiders) has an influence on the outcome of the decision-making process, whose results, however, concern and affect all members of the organization. Under the Charta of the UN, for example, all member states agree to accept and carry out the decisions of the Security Council, even though only a (small) fraction of

\footnotetext{
${ }^{1}$ Article 4 (3) of the Protocol on the Enlargement of the European Union reads as follows: "The Council, acting unanimously after signing the treaty of accession of the twenty-seventh Member State of the Union shall adopt:

- the number of Members of the Commission,

- the implementing arrangements for a rotation system based on the principle of equity containing all the criteria and rules necessary for determining the composition of successive colleges automatically on the basis of the following principles: (a) Member States shall be treated on a strict equal footing as regards determination of the sequence of, and the time spent by, their nationals as Members of the Commission; consequently, the difference between the total number of terms of office held by nationals of any given pair of Member States may never be more than one; (b) Subject to point (a), each successive college shall be so composed as to reflect satisfactorily the demographic and geographical range of all the Member States of the Union."
} 
members is represented in the Council. Rotation in the ECB would imply that not every national central bank governor would have the right to vote (on interest rates or money supply, for instance) in the meetings of the ECB's Governing Council. Rotation in the European Commission means that not every EU member state will have the right to appoint a Commissioner. Since the Commission is the driving force in the legislative process of the EU - by proposing with simple majority of all Commissioners the legislation on which the European Parliament and/or the European Council have to vote - all member states are affected by the Commission's actions, even though not all member states will be represented in future Commissions. ${ }^{2}$

In this paper, we examine the effects of rotation schemes in political organizations. Decision-making of political institutions can, generally, be described as being affected both by the self-interest of the involved parties, but also by a concern for the collective interest of the organization as a whole. One straightforward example one might think of is the legal framework provided by and for the members of an organization as a public good. There is an incentive for the members of a political organization - like the member states of the EU - to shape the draft of the legal framework (like the currently hotly debated EU-constitution) in their own interest. But the legal framework should also promote the common interest of all members of the organization. Such an interaction - and the possible tradeoff - between selfinterest and collective interest is a typical feature of social dilemma situations, such as the provision of a public good, which is characterized by a tradeoff between self-interest and common interest. We would like to argue, therefore, that decision making in political organizations is in many aspects similar to the problems associated with the voluntary contribution to public good provision, i.e. the individual and social outcome of the decisionmaking process hinges on the level of cooperation among members, and there might be a tradeoff between self-interest and the common interest. Pursuing the analogy between public good provision and decision-making in political organizations, one might, then, study the effects of rotation schemes on decision-making in political organizations by addressing the following questions, which constitute the key research agenda of this paper:

(1) Is rotation harmful for cooperation in a group? Put differently, does it crowd out cooperation, compared to a situation without rotation and, hence, encompassing

\footnotetext{
${ }^{2}$ Note that Commissioners according to the EU Treaty must act "in the general interest of the Community, be completely independent in the performance of their duties" and may "neither seek nor take instructions from any government" (Article 213(2) EU). Nevertheless it is a matter of fact that members of the Commission do not act as nationally impartial and as independent of the political interest of the country they are nationals of as the text of the EU Treaty suggests. Else we would not observe such serious political struggles on the composition of the Commission with regard to the nationality of its members.
} 
representation of all organization's members? (2) Do insiders and outsiders differ in their decisions? (3) Do insiders use their option to exploit outsiders? I.e. are the powerful insiders, who control the decision-making process, willing to take into account the interests of outsiders or are they tempted to allocate the public good provided by the institution to the disadvantage of the - at least temporarily - powerless outsiders?

Of course, it would be most desirable to answer these questions by an empirical analysis of real-world institutions where rotation schemes are actually applied. However, analyzing real world institutions bears the problem of possibly confounding the effects of rotation per se with other factors influencing political and economic decision-making, like, for instance, the specific combination of insiders and outsiders or the bundling of multiple issues. Furthermore, in real world organizations with rotation schemes we can only observe behavior of insiders, but not the one of outsiders. The latter, however, might be important in the process of preparing a decision finally taken by the insiders. ${ }^{3}$ Given these limitations of field data, we try to answer our research questions by the use of an experimental study. The methodological approach is in the spirit of Ledyard, who claimed that "although this is an infant science, I believe that mechanism design and testbedding will ultimately become the foundations of policy analysis" (Ledyard, 1995, p. 120). ${ }^{4}$ In particular, experimental methods provide a means to investigate behavior of real subjects under controlled conditions, where one is able to sharply separate different institutional design factors and analyze their influence on actual behavior without perturbing interferences from real world situations.

Naturally, by choosing the experimental method we are forced to boil down a real world institution to its very essentials. This means - as it is always the case in scientific modeling - that we have to abstract from surrounding realities; e.g. in an experiment we are hardly able to implement the intricacies of the political decision-making process in the EU Council of Ministers, the EU-Commission or the UN Security Council. However, concentrating on the structural key-aspects of an institution allows analyzing the behavioral incentives provided by a certain institution much more thoroughly than it would be possible in an empirical field study.

\footnotetext{
${ }^{3}$ For a theoretical analysis of (voting) power of insiders and outsiders in the UN Security Council see, for instance, O’Neill (1996).

${ }^{4}$ Recently, policy-oriented experiments have become increasingly accepted as a tool to explore different (political) institutional designs. Irlenbusch et al. (2003), for example, have studied the voting process in the Stability and Growth Pact in the European Monetary Union. In a similar spirit, Riedl and van Winden (2001) have investigated the economic effects of a change in the Dutch tax regime which had been envisaged by the Dutch government, but which was postponed after having heard about the experimental results.
} 
The remainder of the paper is organized as follows. Section 2 presents our experimental design in detail. Results are presented in Section 3. Section 4 concludes.

\section{Experimental setup}

As already mentioned, our experimental design builds on a public good game, since many aspects of decision-making in political organizations can be considered to be sufficiently close in its incentive structure to the provision of a public good. Let us continue our example of proposing and implementing new legislation. Clearly, the results of the legislative process may be of varying quality. Members of an organization may contribute more or less to the quality of the public good "legislation" by providing costless expertise or by supporting (or not vetoing) a specific law in the decision-making body. The more cooperative the members of an organization are, the more efficient may be the provision of the public good.

In the case of encompassing representation of all members in the decision-making body of the organization, all members can contribute on equal footing to the public good and no member can be excluded from the benefits of the public good. In our experimental design, we will introduce a control treatment which serves to account for this case of encompassing representation.

With a rotation scheme, all members of an organization may contribute to the public good, but only the current insiders have the power to determine its precise characteristics. That means, basically, that the insiders can allocate the benefits of the public good among all members, both insiders and outsiders. Please note that the term "public good" typically implies "non-excludability" from the benefits of a public good for any of the group members. However, in reality, the benefits need not be equal across group members. One can easily think of examples for public goods which are highly valuable for some members (for instance legal limitations on transit traffic for inhabitants of densely populated areas creating the public good of clean air), whereas they may be worthless or even detrimental for other members of a community (such as traffic limitations for cargo companies). In such cases, which are quite frequent in politics, it seems to be of importance having the power to decide on the specific characteristic of the public good, i.e. to be an insider and not an outsider in our terminology. Our rotation treatment will account for such situations. 


\subsection{Experimental design}

We have set up groups of $n=3$ subjects each. Group members stay together for 15 rounds of a repeated public good game. At the beginning of each round, each subject receives an endowment of 20 tokens. The endowment has to be allocated to two different accounts: a group account (described as pot X; see the Appendix for the experimental instructions) and a private account (pot $\mathrm{Y}$ ). Contributing to pot $\mathrm{X}$ is in this case the cooperative move, i.e. the contribution to the public good, whereas any token allocated to pot $\mathrm{Y}$ is a private good. In both treatments, the marginal per capita return of a contribution $g_{i}$ of subject $i$ to the public good (alternative $\mathrm{X}$ ) is set at 0.5 , whereas the marginal per capita return from contributing to the private good (alternative $\mathrm{Y}$ ) is set at 1 .

In the control treatment, all group members benefit equally from the public good provided by the voluntary contributions of group members. Thus, each group member's profit in a given round can be expressed as

$$
\pi_{i}=20-g_{i}+0.5 \sum_{j=1}^{3} g_{j} .
$$

In the rotation treatment, the benefits from the public good need not be equal for all group members. In particular, the distribution of benefits depends upon the decisions of the insiders. In each round, two group members are determined to be insiders, whereas the third group member is the outsider. The sequence of the predetermined rotation scheme is shown in Table 1, and it is common knowledge in the experiment.

Table 1: Rotation scheme

\begin{tabular}{lccc}
\hline \hline & Member 1 & Member 2 & Member 3 \\
\hline Round 1 & IN & IN & OUT \\
Round 2 & IN & OUT & IN \\
Round 3 & OUT & IN & IN \\
Round 4 & IN & IN & OUT \\
$\ldots$ & $\ldots$ & $\ldots$ & $\ldots$ \\
Round 14 & IN & OUT & IN \\
Round 15 & OUT & IN & IN \\
\hline \hline IN = insider; OUT = outsider. & &
\end{tabular}

Like in the control treatment, group members have to decide also in the rotation treatment at first on the contribution to the public good (pot $\mathrm{X}$ ) at the beginning of each 
round. Before group members are informed about the contributions of the two other group members, the two insiders have to determine a threshold $t \in[0 ; 21]$. This threshold determines whether the outsider benefits from the public good or not. If the outsider's contribution $g_{o}$ is at least as large as the maximal threshold stated by both insiders, then the public good accrues equally to all group members and equation (1) from above applies.

However, if the outsider's contribution $g_{o}$ is strictly smaller than at least one of the two thresholds, then the outsider gains nothing from the public good and earns only $\pi_{o}=20-g_{o}$, whereas both insiders can share the benefits from the public good in a more profitable way than in case they had accepted the outsider's participation in the public good. In particular, the insiders' profit is, hence, given by equation (2), which implies that their marginal per capita return from contributing to the public good is raised from 0.5 to 0.75 .

$$
\pi_{i n}=20-g_{\text {in }}+0.75\left(\sum_{i n=1}^{2} g_{j}+g_{o}\right) .
$$

Note that our threshold rule implies unanimous decision-making of insiders, since the higher of the two thresholds determines whether the outsider is granted a share in the public good. Note also that if one of the insiders sets a threshold of $t=21$, the outsider is definitely excluded from the benefits of the public good, irrespective of his contribution to it.

As regards information conditions, all decisions on contributions and thresholds were made public within a group at the end of each round. Decisions on contributions and thresholds could be linked to single group members via their subject number. However, subject numbers could not be linked to any person.

The experiment was run computerized (using z-Tree by Fischbacher, 1999) at the University of Innsbruck and lasted slightly less than one hour per session. In total, we had 108 participants from various disciplines (mainly economics, politics, medicine and psychology), which yielded 18 independent observations per treatment. At the beginning of the experiment, participants were randomly assigned subject numbers and seated in cubicles which separated subjects from each other. They got written instructions that were read aloud by the experimenter. The instructions were phrased in neutral terms, and remaining questions after reading the instructions were answered privately. We told participants in advance that their decisions and their final payment would remain confidential. The exchange rate was set at 3 Euro-Cents for 1 token. Average final payof amounted to $11.1 €$ per subject. 


\subsection{Predictions}

It is straightforward to show that free riding is a dominant strategy for payoffmaximizing subjects in our public good game, because $\partial \pi_{i} / \partial g_{i}<0$ in any treatment, irrespective of whether outsiders share the benefits of the public good in the rotation treatment or not, i.e. irrespective of whether equation (1) or (2) applies. Since the experiment has a finite and publicly known number of rounds, backward induction yields the only subgame-perfect Nash equilibrium of $g_{i}=0$ in any period. Thus, from a game-theoretic point of view, there should be no difference (i) between the two treatments and (ii) between insiders and outsiders in the rotation treatment.

A similar line of reasoning helps to solve for the threshold choice. In the final round, the two insiders should not grant the outsider a share in the public good, irrespective of the outsider's contribution. Thus the threshold should be prohibitive, i.e. $t=21$. By a backward induction argument this also holds for earlier rounds. Note that the choice of thresholds is actually irrelevant if all group members choose their dominant strategy to contribute nothing. A small probability of a deviation from the subgame-perfect Nash equilibrium by other players would, however, justify a prohibitive threshold choice also theoretically.

Of course, a huge number of studies on linear public good games has shown that subjects typically do not choose dominant strategies, but rather start our with significant contributions of about $50 \%$ of their endowment that decline in the course of repetition towards zero contributions (for a survey see Ledyard, 1995). From this behavioral point of view, one might expect differences between insiders and outsiders in the rotation treatment for the following reason: Research on the behavioral consequences of democratic participation rights (Frey, 1994) has shown that excluding subjects from democratic participation or limiting their participation rights - as is the case for outsiders in our rotation treatment - has detrimental effects on their level of cooperation. Such an effect has been detected, for instance, concerning the degree of actual tax evasion (Pommerehne and WeckHannemann, 1996) or the provision of public goods in experimental public good games (Sutter and Weck-Hannemann, 2003). Hence, we should expect lower contributions from outsider than from insiders. Whether aggregate contributions in the rotation treatment are, then, lower than in the control treatment is hard to predict, because it might be the case that the rotation scheme per se has a positive effect on insiders' contributions - compared to the control treatment - which might level out the lower contributions of outsiders. 


\section{Experimental results}

\subsection{Is rotation harmful for cooperation in a group?}

Table 2 provides a descriptive overview of our experimental results. Averaging over all 15 rounds, we obtain average contributions of 8.12 tokens (out of 20) in our control treatment, and 10.35 in the rotation treatment. Applying a Mann-Whitney U-test, we cannot reject the null hypothesis of no difference between the aggregate contribution levels in both treatments. We can, therefore, conclude that rotation has no significant influence on cooperation levels in the aggregate.

Table 2: Descriptive overview

\begin{tabular}{lcc}
\hline \hline & control & rotation \\
\hline number of groups & 18 & 18 \\
average contribution per subject and round & 8.12 & 10.35 \\
average contribution of INs $\left(g_{i n}\right)$ & & 12.46 \\
average contribution of OUTs $\left(g_{o}\right)$ & 6.12 \\
$\begin{array}{l}\text { average number of OUTs for which } \\
\quad g_{o} \geq \max \left\{t_{i n}\right\}, \text { in }=1,2\end{array}$ & 1.80 \\
$\begin{array}{l}\text { average thresholds }\left(t_{i n}\right) \\
\text { average difference between contributions } \\
\quad \text { of INs and thresholds }\left(g_{\text {in }}-t_{\text {in }}\right)\end{array}$ & 17.22 \\
\hline \hline
\end{tabular}

However, when looking at the development of average contributions across the 15 rounds (shown in Figure 1), we find that average contributions are about the same in both treatments in the first 4 rounds, but from the fifth round on, average contributions in the control treatment are strictly lower than in the rotation treatment, with a somewhat more marked decay of average contributions in the control treatment. A simple OLS-regression shows that the estimated decline of average contributions is 0.28 tokens per round and subject in the rotation treatment, but 0.58 tokens in the control treatment, with the difference being significant on the 5\% level according to a Chow-test. This latter result implies that average contributions are significantly more stable in the rotation treatment than in the control treatment, even though overall average contributions show no significant difference. In the following, we will restrict our analysis to the rotation treatment and examine differences between insiders and outsiders and the effects of thresholds, determined by insiders, on the contributions of outsiders. 
Figure 1: Average contributions to the public good

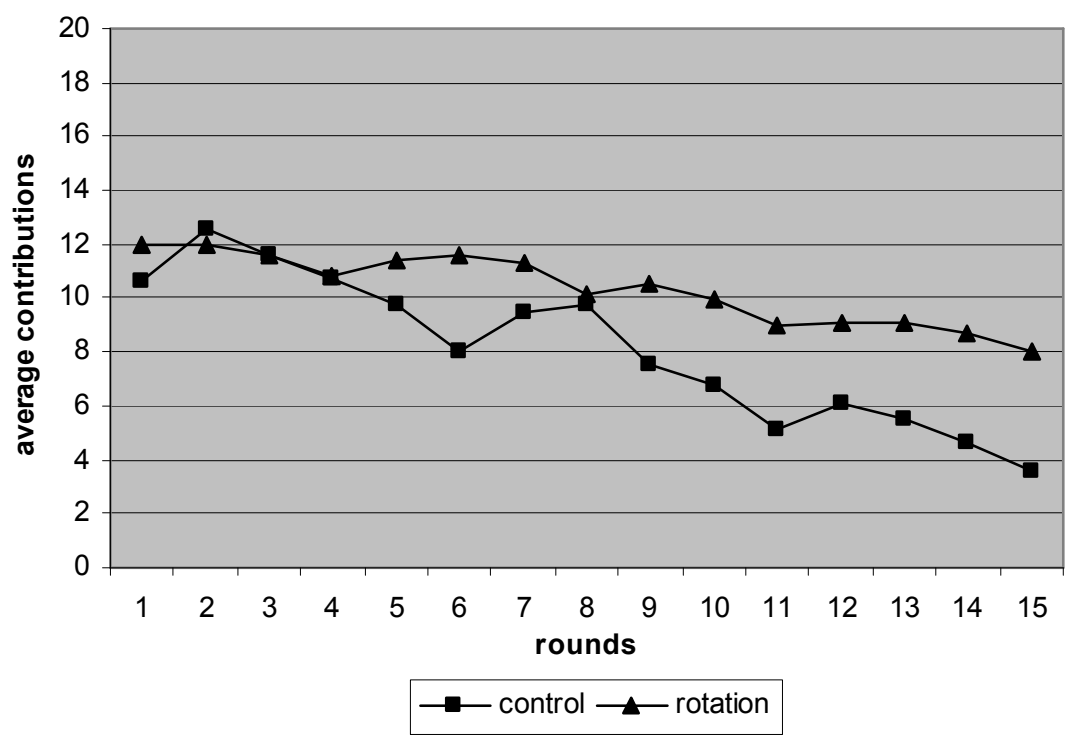

\subsection{Do contributions differ between insiders and outsiders?}

In Figure 2, we display average contributions of insiders and outsiders in the rotation treatment. It is obvious that contributions of insiders remain quite stable over the 15 rounds, declining only slightly in the second half of the experiment. Overall average contributions are 12.5 tokens, which is significantly larger than outsiders' contributions of 6.1 tokens $(p<0.01$; two sided Wilcoxon signed-ranks test with average contributions of insiders and the contribution of the outsider within a single group as units of observation; $N=18$ ). In sharp contrast to the development of insiders' contributions, contributions by outsiders display a remarkable decline from the second to the third round and a gradual, even though less pronounced, decay afterwards.

The difference in contributions between insiders and outsiders is not only significant between subjects (in a given round), but also within subjects across rounds, meaning that individual subjects contribute significantly more in the role of insider than in the outsider role ( $p<0.01$, two-sided Wilcoxon signed-ranks test; $N=54)$. This result is remarkable because it confirms that the same person acts very differently, depending clearly upon the role she is in. In the next subsection we will dig deeper into the reasons for the different contributions of insiders and outsiders.

Interestingly, we find that insiders in the rotation treatment contribute significantly more than subjects in our control treatment ( $p<0.05$; two-sided Mann-Whitney-U-test; $N=$ 36), as could almost be guessed from Figure 3. There is, however, no statistically significant 
difference between contributions of outsiders in the rotation treatment and subjects in the control treatment.

Figure 2: Average contributions of insiders and outsiders in the rotation treatment

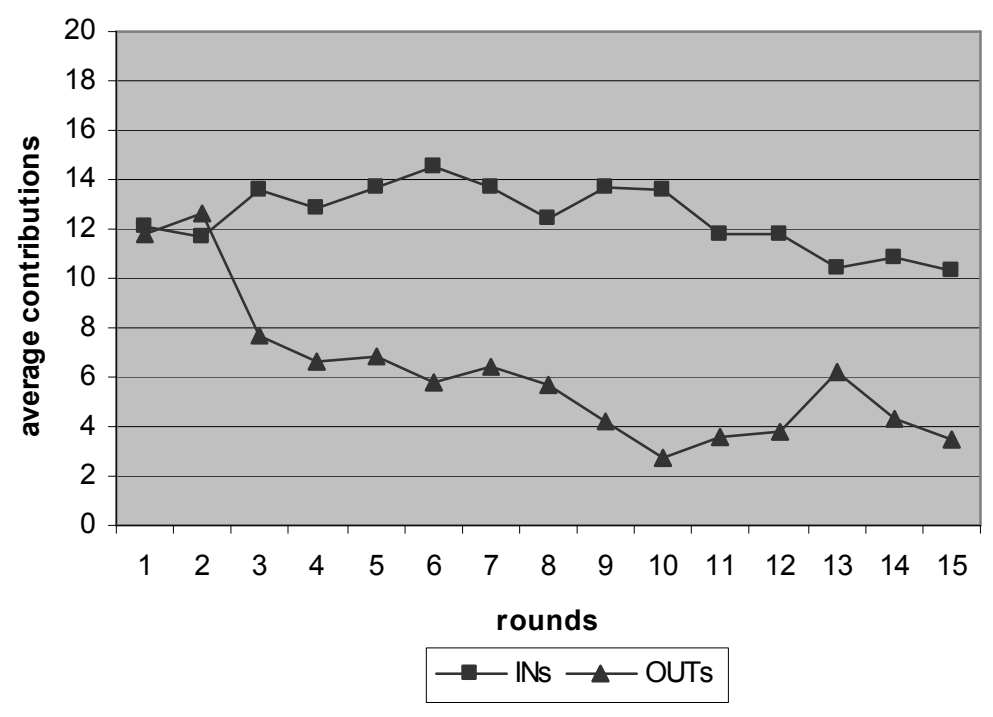

Figure 3: Contributions of insiders and in the control-treatment

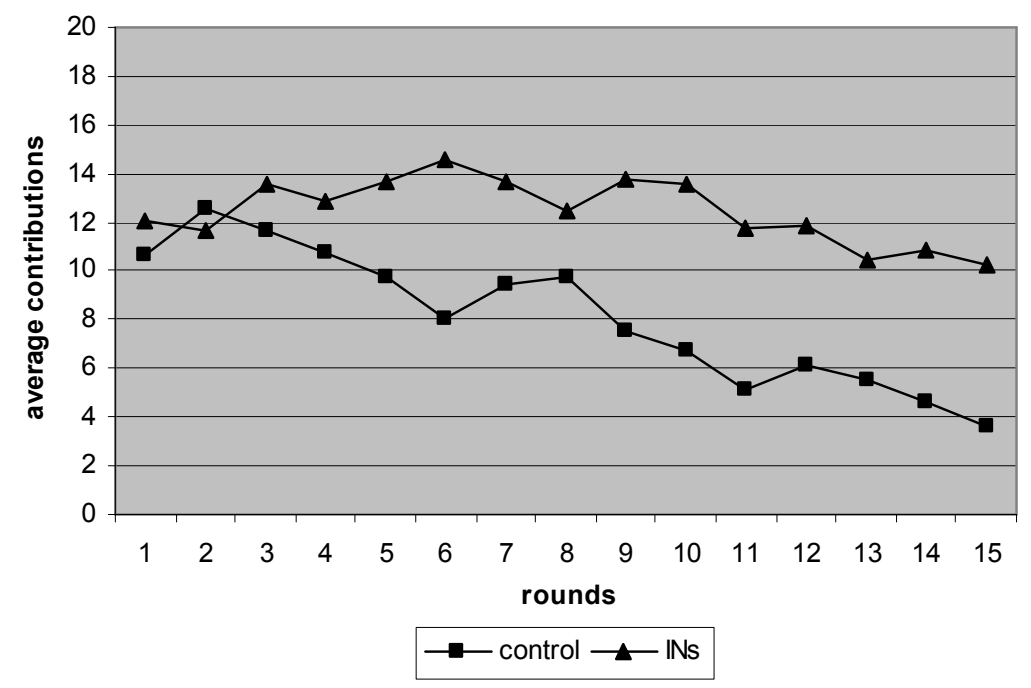

\subsection{Thresholds, exclusion and the determinants of contributions}

Figure 4 indicates the average threshold levels determined by insiders. For ease of comparison, we also show insiders' actual contributions. It is noteworthy that average thresholds (of 17.2) are significantly larger than actual contributions of insiders (12.5) both on average and in each single round ( $p<0.01$; two-sided Wilcoxon signed-ranks test). 
Figure 4: Contributions and thresholds of insiders in the rotation treatment

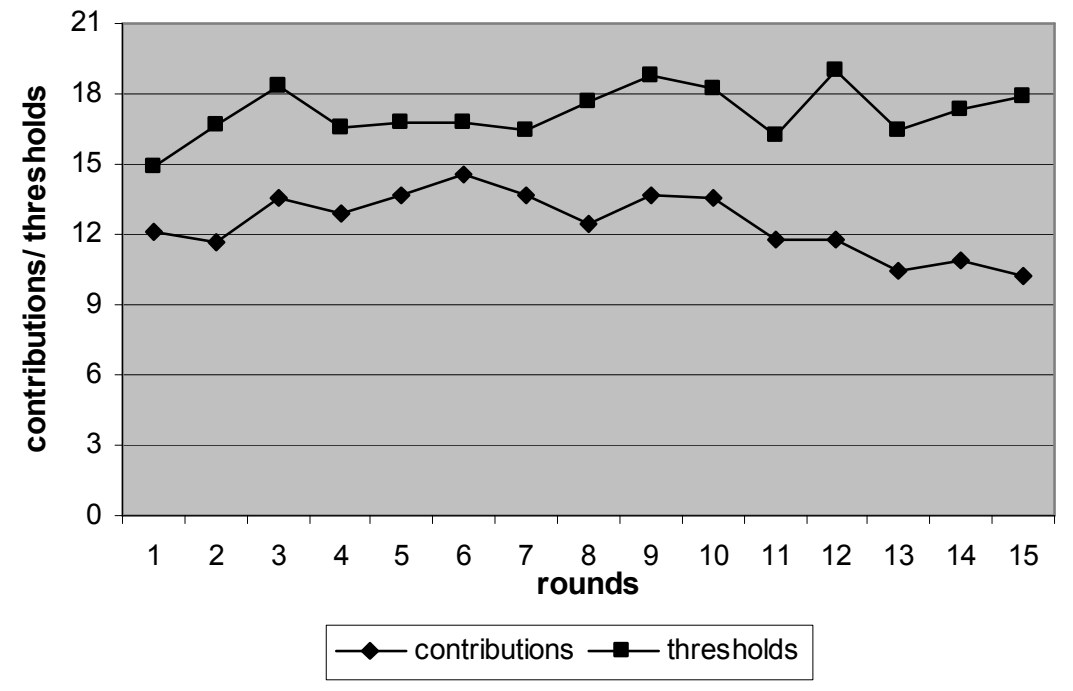

Figure 5 shows the absolute frequency of single thresholds chosen by insiders. Recall that the theoretical prediction (under the assumption of payoff-maximization of insiders) would be to choose 21 tokens as threshold. A threshold of 21 is actually chosen in 272 out of 504 possible cases $(50.4 \%)$. The second most frequent threshold choice is 20 tokens (69 times, respectively $12.8 \%$ ). It is no surprise, then, that outsiders are very rarely granted a share in the public good ${ }^{5}$, as can be seen from Figure 6.

Figure 5: Frequency distribution of chosen thresholds

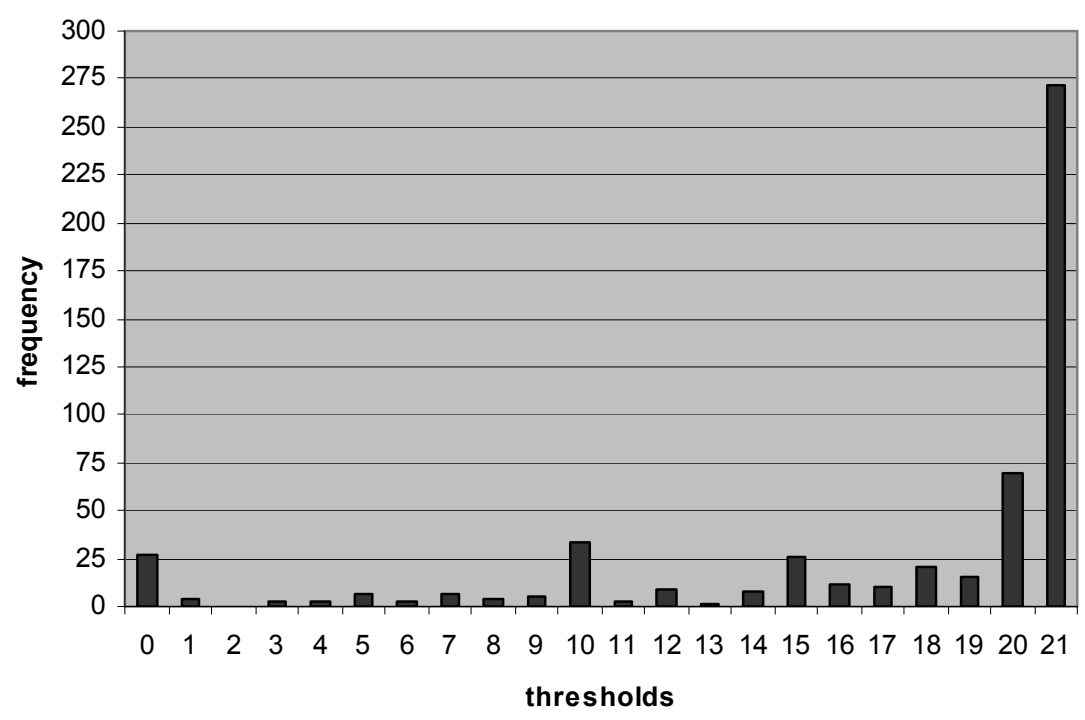

\footnotetext{
${ }^{5}$ Note that the maximum number is 18 , since we have 18 independent group observations.
} 
Figure 6: Number of outsiders being granted a share in the public good for each round

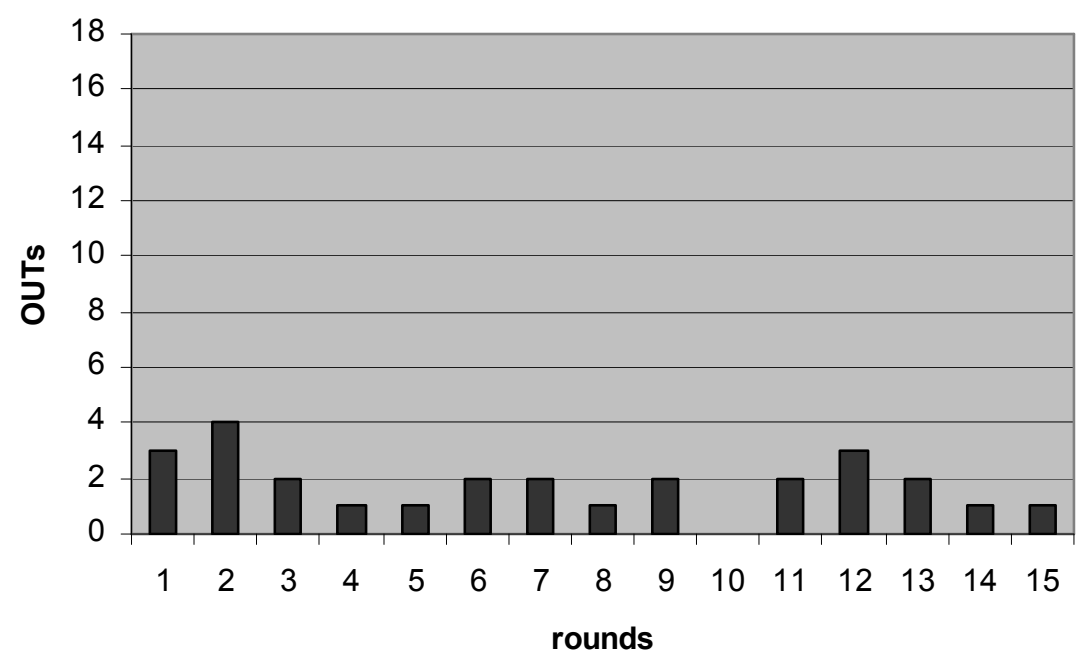

In fact, outsiders meet or exceed the maximum threshold only 27 times (a success rate of $10 \%$ ), while they are excluded from the benefits of the public good 243 times. Interestingly, we find a significantly positive correlation between average group contributions and the average number of outsiders being granted a share in the public good (Spearman rank correlation coefficient of $0.54, p<0.05$ ), which means that not excluding outsiders is typically associated with higher average contributions in a group, and, hence, higher efficiency and profits. Yet, these potential efficiency gains are not seized in $90 \%$ of cases, leading us to the conclusion that insiders try to and actually exploit outsiders, much to the detriment of the whole group.

In the following, we are going to examine the influence of chosen thresholds on outsiders' contributions. We start by simply asking how outsiders react to being excluded from the public good. Taking only the first exclusion experience of outsiders, which is most interesting, the reaction depends on the maximum threshold which applied. If the applicable maximum threshold is below 21 tokens, then outsiders increase their contribution in 7 cases and reduce it in 3 cases in the next round where they are again outsiders. However, if the maximum threshold is equal to 21 tokens, then outsiders increase their contributions only in 5 cases, but reduce it in 22 cases. The reaction to thresholds (an increase or a reduction; unchanged contribution levels are not considered) is significantly different between prohibitive and non-prohibitive thresholds $\left(\chi^{2}=8.83 ; d f=1 ; p<0.01\right)$. We can conclude that relatively low thresholds provide, at first, encouragement for increasing contributions, whereas prohibitively high thresholds (of 21 tokens) discourage contributions to the group public good. 
Table 3 provides the estimates from a pooled OLS-regression ${ }^{6}$, with the contribution of the outsider in round $t$ as the dependent variable and the average contribution in the group in round $t-1$ as well as dummy variables on excluding the outsider of round $t-1$, respectively $t-3$, as independent variables. The dummy for excluding the outsider in the previous round refers to the most recent experience with outsiders. Considering the exclusion of the outsider in round $t-3$ is important because it catches the current outsider's (in round $t$ ) last experience as outsider.

Table 3: Determinants of outsiders' contributions

\begin{tabular}{lcc}
\hline \hline & coefficient & probability \\
\hline average group contribution in round $t-1$ & 0.21 & 0.002 \\
outsider excluded in $t-1$ & -10.96 & 0.001 \\
outsider excluded in $t-3$ & -6.65 & 0.001 \\
constant & 0.95 & 0.099 \\
\hline Adjusted $\mathrm{R}^{2}$ & 0.39 & \\
Total panel (balanced) observations & 216 & \\
\hline \hline
\end{tabular}

dependent variable: contributions of outsider in round $t$.

All three variables are highly significant for the contribution of the outsider in round $t$. The higher the average contribution in the group in the previous round, the higher is the outsider's contribution. This finding is consistent with the growing body of literature on conditional cooperation, which states that people are willing to contribute more to a public good the more others contribute and that they reduce their cooperation if they are exploited by free-riders (Fischbacher et al., 2001; Keser and van Winden, 2000; Sutter and WeckHannemann, 2003). However, the marginal effect of the group's average contribution in the previous round is relatively low in comparison to the effect of excluding outsiders. If the outsider has been excluded in the previous round (dummy variable coded as +1 ), the estimated contribution of this round's outsider is almost 11 tokens lower than in case the outsider has not been excluded in the previous round (coded as 0 ). The effect of having been excluded in round $t-3$ is somewhat smaller (an estimated reduction of 6.6 tokens), but still highly significant. In summary, excluding outsiders discourages their contributions to the public good and has, thus, detrimental effects on the social surplus generated in the group.

\footnotetext{
${ }^{6}$ A pooled regression is used because any subject is in the role of outsider 5 times (every third round).
} 


\subsection{Discussion of some notable results}

In this section, we address three aspects of our experimental results which we deem in need of some further discussion. (1) Why do insiders contribute more than outsiders, and even more than subjects in the control treatment? (2) Why do insiders set higher thresholds than their own contribution levels? (3) Why does the same subject contribute very little when being an outsider, but relatively much when being an insider?

One might advance a straightforward explanation for the first question. In comparison with the control treatment, insiders face a higher marginal per capita return (MPCR) of 0.75 instead of 0.5 , if they exclude the outsider, which is the predominant case. It has been shown in public good experiments that contributions rise almost monotonically with an increase in the marginal per capita return (Ledyard, 1995). This is due to a relative price effect, because contributing to the public good gets relatively more profitable.

To address the second and the third question, we would like to start by noting that insiders enjoy the great benefit of the right to determine thresholds. Setting a high threshold provides an insurance against a possible exploitation by outsiders through free-riding. The instrument of setting thresholds, therefore, either induces the outsiders to contribute more than the (high) threshold - which is profitable for insiders - or excludes the outsider from the public good - which raises the MPCR for the insiders and protects them against exploitation. Both effects are clearly advantageous for insiders and provide incentives for relatively high contributions and even higher thresholds. However, the possibility of being excluded provides an incentive for the outsiders to reduce contributions because they could be wasted to the benefit of insiders. Note that setting high(er) thresholds is also compatible with the concept of conditional cooperation which was already discussed in the previous subsection.

\section{Conclusion}

Our experimental study has shown that rotation schemes need not change the degree of voluntary cooperation in groups - compared to a system of an encompassing representation of all members of a group. Hence, rotation may be regarded a viable instrument to address the representation/efficiency dilemma in large political organizations.

However, there are some notable behavioral consequences of rotation. First, there is a strong temptation for insiders to exploit outsiders. In practice, insiders can achieve this, for instance, by shaping joint legislation in their favor and to the disadvantage of temporarily 
powerless outsiders. Second, outsiders react to being exploited by insiders through the reduction of their voluntary contributions to the public good, which is inefficient from a social viewpoint and reduces also insiders' payoffs.

Although we do not want to over-interpret our results, we are confident that some tentative policy implications can be drawn from our study. It is, first of all, comforting to note that rotation schemes per se do not seem to affect the outcome of decision-making processes in political institutions negatively. Given that the rotating order is fair, i.e. each group member acts equally often and in a fixed order as insider and outsider, contribution levels are even higher than in our control environment, although the difference is not significant. Thus, we cannot detect any reason from our results why the implementation of rotation schemes in EU institutions - as proposed for the EU Commission and discussed for the ECB - as a means to solve the representation/efficiency-dilemma should be opposed.

What we clearly find is a strong inclination of insiders to fix thresholds at prohibitively high levels which exclude most outsiders from the benefits of the public good. This result shows that insiders actually exploit their power (as many of the UN Security Council's permanent members are perceived to do). Such a tendency may, however, lead to undesirable outcomes from a social perspective. Therefore, more research seems to be warranted how, for instance, the implementation of safeguards can limit the possible negative effects of rotation schemes on outsiders. Such safeguards may be treaties, qualified majority requirements for the decisions taken by insiders or similar formal limitations to the decisionmaking process. These safeguards could prove to be particularly important in organizations where some players act less often as insiders than others, as is, for instance, the case in the UN Security Council. Finally, it might be worthwhile to examine in future research projects under which conditions the thresholds set by insiders can rather work as an incentive to trigger high contribution levels of outsiders, instead of as a means to exploit outsiders, which has been shown to be detrimental to the welfare of all group members by driving down outsiders' contributions.

\section{References}

Baldwin, R. E., Berglöf, E., Giavazzi, F., Widgren, M. (2001), Eastern enlargement and ECB reform. Swedish Economic Policy Review 8: 15-50. 
Buchanan, J. M., Tullock, G. (1962), The Calculus of Consent. Ann Arbor, University of Michigan Press.

de Grauwe, P. (2002), Challenges for Monetary Policy in Euroland. Journal of Common Market Studies 40: 693-718.

Felsenthal, D. S., Machover, M. (2001), The Treaty of Nice and qualified majority voting. Social Choice and Welfare 18: 431-464.

Fischbacher, U. (1999), Z-tree: Zurich Toolbox for Readymade Economic Experiments. Working Paper No. 21, Institute for Empirical Research in Economics, University of Zurich.

Fischbacher, U., Gächter, S., Fehr, E. (2001), Are people conditionally cooperative? Evidence from a public goods experiment. Economics Letters 71: 397-404.

Frey, B. S. (1994), Direct democracy: Politico-economic lessons from Swiss experience. American Economic Review, Papers and Proceedings 84: 338-342.

Heisenberg, D. (2003), Cutting the Bank down to size: Efficient and legitimate decisionmaking in the European Central Bank after enlargement. Journal of Common Market Studies 41: 397-420.

Keser, C., van Winden, F. (2000), Conditional cooperation and voluntary contributions to public goods. Scandinavian Journal of Economics 102: 23-39.

Irlenbusch, B., Leopold-Wildburger, U., Schütze, J., Sutter M. (2003), Voting in EMU - An experimental study on institutional innovation and the role of communication in the Stability and Growth Pact. Journal of Common Market Studies 41: 645-664.

Ledyard, J. O. (1995), Public goods: A survey of experimental research. in: Kagel, J. H., Roth, A. E. (eds.), The Handbook of Experimental Economics. Princeton, Princeton UP: 111-194.

O’Neill, B. (1996), Power and satisfaction in the United Nations Security Council. Journal of Conflict Resolution 40: 219-237.

Pommerehne, W. W., Weck-Hannemann, H. (1996), Tax rates, tax administration and income tax evasion in Switzerland. Public Choice 88: 161-70.

Riedl, A., van Winden, F. (2001), Does the wage tax system cause budget deficits? A macroeconomic experiment. Public Choice 109: 371-394.

Sutter, M., Weck-Hannemann, H. (2003), On the effects of asymmetric and endogenous taxation in experimental public good games. Economic Letters 79: 59-67.

Wieser, T. (2001), Comment on Baldwin, Berglöf, Giavazzi and Widgren: Eastern enlargement and ECB reform. Swedish Economic Policy Review 8: 51-55. 


\section{Appendix}

Instruction sheet for the rotation treatment $^{\S}$ (Originally in German)

\section{Welcome to the experiment and thank you for participating!}

From now on, do not speak with other participants.

\section{General information}

This experiment analyzes economic decision-making. You can earn 'real' money, which is paid to you in cash at the end of the experiment. During the experiment you are asked to make decisions. Your own decisions as well as decisions of other players determine your final payment according to the rules in the instructions. The whole experiment lasts for about one hour. At the beginning you receive detailed instructions. If you want to ask questions after reading the instructions, please raise your hand. An experimenter will, then, come to you and answer your questions privately.

\section{The experiment}

\section{Groups}

Before the experiment starts, groups consisting of three participants are formed; assignment is random. You will know neither during the experiment nor after it with whom you have formed a group. Your decisions therefore remain anonymous.

The experiment lasts for 15 rounds. During the whole experimental session group composition remains constant.

The three subjects of a group will be assigned an identification code in the following form:

- group member 1

- group member 2

- group member 3

These codes are not fixed across rounds. The following table shows how identification codes change in every round for the three members of a group (i.e. subjects $1-3$ ).

\footnotetext{
$\S$ The instruction sheet for the control treatment is available upon request from the authors.
} 


\begin{tabular}{|l|l|l|l|}
\hline & Subject 1 & Subject 2 & Subject 3 \\
\hline Round 1 & 1 & 2 & 3 \\
\hline Round 2 & 2 & 3 & 1 \\
\hline Round 3 & 3 & 1 & 2 \\
\hline Round 4 & 1 & 2 & 3 \\
\hline$\cdots$ & $\ldots$ & $\ldots$ & $\ldots$ \\
\hline Round 14 & 2 & 3 & 1 \\
\hline Round 15 & 3 & 1 & 2 \\
\hline
\end{tabular}

\section{Initial endowment and alternatives}

Each participant receives an initial endowment of $\mathbf{2 0}$ tokens at the beginning of each round.

These token can be allocated to two alternatives (saving for later rounds is not permitted):

1. You can give 0 to 20 tokens into pot $\mathbf{X}$. The sum of all contributions within your group to pot $\mathrm{X}$ will be multiplied by 1.5 and distributed among group members as described in stage 3.

2. You can give 0 to 20 tokens into pot $\mathbf{Y}$. Your individual tokens in pot $Y$ are directly added to the sum of your tokens that finally determines your profit.

\section{3 stages per round}

Each round of the experiment comprises three stages:

- Stage 1 consists of a decision of each player.

- In stage 2 group members 1 and 2 take a decision.

- In stage 3 results in tokens are shown to every group member.

\section{Stage 1: Subjects submit their contribution into pot $X$}

You decide how many of the 20 tokens of your endowment you want to put into pot X. Your contribution can range in integer amounts from 0 to 20 . The remainder to 20 goes automatically in pot $\mathrm{Y}$.

\section{Stage 2: Group members 1 and 2 determine a level}

In stage 2 group members who have the identification code 1 and 2 in the respective round take a decision. If you are in the role of member 1 or 2 you have to determine a threshold. The level indicates how many tokens member 3 has to allocate at least to pot $\mathrm{X}$ in stage 1 in order 
to get a share in the profit of pot $X$. The threshold can range from 0 to 21 . If you enter the value 21, group member 3 definitely will not receive a share in the profit of $X$.

\section{Stage 3: Results and earnings per round}

The outcome of decisions in stages 1 and 2 can be described in the following way:

- If the contribution of group member 3 into pot $X$ is higher or at least as high as both of the thresholds determined by members 1 and 2, the sum of all contributions (group members 1, 2 and 3) in pot $\mathrm{X}$ is multiplied by 1.5 and, then, divided equally among all three players. That means that for each token you allocate to pot $\mathrm{X}$ you receive 0.5 tokens, and both other group members also receive 0.5 tokens each.

Your profit in this case is as follows: To the earnings from pot $\mathrm{X}$, tokens allocated to pot $\mathrm{Y}$ have to be added. Mathematically:

$$
\begin{aligned}
& \text { Profit }(\text { for group member } \mathbf{i})=(20-\mathbf{x})+(S * 1.5) / 3 \\
& x \ldots \text { contribution of player } i \text { into pot } X \\
& S \ldots \text { sum of contribution of all group members in pot } X
\end{aligned}
$$

- If the contribution of group member 3 into pot $X$ is lower than at least one of the thresholds of members 1 or 2, the sum of all contributions (group member 1, 2 and 3) in pot $\mathrm{X}$ is multiplied by 1.5 and then divided equally among group members 1 and 2. Player 3 in this case does not earn anything from pot X. He only earns the tokens which he allocated to pot $\mathrm{Y}$.

Mathematically:

$$
\begin{aligned}
& \text { Profit (for group members } 1 \text { or } 2)=(20-x)+(S * 1.5) / 2 \\
& \text { Profit (for group member } 3)=20-x
\end{aligned}
$$

After each round, you receive information about contributions of all group members, thresholds of members 1 and 2 and your personal profit on your screen.

\section{End of the experiment}

After 15 rounds the experiment ends. Results of single rounds in terms of tokens are added up and converted into euros. The exchange rate is:

$$
1 \text { tokens }=3 \text { Euro-Cents }
$$

You will be paid your profit privately and in cash right after the experiment. 